\title{
Prevalence and Antibiotic Resistance Pattern of Escherichia coli Isolated from Raw Dairy Milk
}

\author{
Abul Hasan', Md. Ahsanur Reza², Farzana Islam Rume', Mirza Mienur Meher', \\ Md. Shafiullah Parvej ${ }^{3}$, AKM Mostafa Anower ${ }^{*}$ \\ ${ }^{1}$ Department of Microbiology and Public Health \\ ${ }^{2}$ Department of Physiology and Pharmacology, Faculty of Animal Science and Veterinary Medicine, Patuakhali Science and Technology \\ University, Barisal, Bangladesh. \\ ${ }^{3}$ Graduate School of Human Life Science, Osaka City University, Osaka, Japan. \\ A R T I C L E I N F O \\ A B S T R A C T

\section{Research Article} \\ Received 08 January 2018 \\ Accepted 02 August 2018 \\ Keywords: \\ Dairy milk \\ E. coli \\ Total aerobic mesophilic count \\ Coliform count \\ Drug resistance \\ milk and milk products. To assess the role of dairy milk as the source of drug resistant $E$. \\ coli, we examined 50 raw dairy milk samples (25-farm milk +25 -market milk) from \\ some selected areas of Bangladesh by cultural, morphological, biochemical and \\ antimicrobial sensitivity tests. In the preliminary observation, the mean total aerobic \\ mesophilic count of market and farm raw milk samples were 8.98 and $8.68 \mathrm{log} \mathrm{CFU} / \mathrm{ml}$, \\ while mean coliform count were 4.20 and $3.03 \log \mathrm{CFU} / \mathrm{ml}$ respectively. Thirty-three $E$. \\ coli isolates were recovered from collected samples (66\% 33 of 50) and this pathogen \\ was more prevalent in market milk $(76 \%, 19$ of 25$)$ than farm milk $(56 \%, 14$ of 25$)$. In \\ addition, most of the isolated $E$. coli exhibited resistance against ampicillin and \\ cefotaxime. This result shows that, the raw dairy milk and its products could be a source \\ of human drug resistant $E$. coli.
}

\footnotetext{
*Corresponding Author:

E-mail: anower@pstu.ac.bd
}

DOI: https://doi.org/10.24925/turjaf.v6i9.1108-1113.1788

\section{Introduction}

Diarrheagenic Escherichia coli continue to pose global threat for infant diarrhea, travelers' diarrhea, hemorrhagic colitis and hemolytic uremic syndrome. $E$. coli usually harbor harmlessly to the intestinal tract of mammals; however, in the exhausted or immunosuppressed host, or when intestinal barriers are contravened, nonpathogenic strains of $E$. coli can cause serious illness (Erkmen and Bozoglu, 2016). About 70\% of the childhood death in the developing countries are contributing to diarrheal diseases (Tulloch and Richards, 1993). In addition, it is considered as the second cause of child death worldwide according to the global burden disease report of the world health organization (Kosek et al., 2003). The frequencies of the pathogen vary with geographic region and depend on the socioeconomic and sanitary conditions achieved in the region or country (Black et al., 2010). About 34\% of total diarrheal episodes in Bangladesh are due to diarrheagenic E. coli (ICDDR, 2002) and $20 \%$ of all diarrheal cases is associated with enterotoxigenic E. coli (Qadri et al., 2005). Bovine animals and their products are considered as one of the sources of pathogenic E. coli worldwide. Hassan et al. (2014) found $75 \%$ of healthy cattle in
Bangladesh are the natural reservoir of E. coli, they also reported $43.33 \%$ shiga toxin producing $E$. coli (STEC) in cattle feces, which might be the source of STEC in Human (Hassan et al., 2017). Wang et al. (2017) reported about 75, 26 and $45 \%$ of enteropathogenic E. coli (EPEC), stx 1 and stx 2 genes respectively in cattle fecal samples collected from Japan. They also informed that patient's strain of atypical enteropathogenic E. coli (aEPEC) were closer to bovine strain (Wang et al., 2013). There are reports suggesting that ruminants could shed and spread E. coli to humans through fecal contamination of meat and milk (Elder et al., 2000; Asakura et al., 2001; Naidu et al., 2007).

Major modes of transmission of diarrheagenic E. coli are consumption of contaminated foods and drinks, animal products and contact with farm animals (Kassenborg, 2004). Milk might be a source of E. coli for human and could be contaminated with food borne pathogen during milking process from the milking personnel, utensils used for milking (Rehman et al., 2014) or microorganisms may enter the udder through teat canal from the environment (Smith et al., 2007). The presence of pathogen in milk largely depends on fecal 
contamination (Aycicek et al., 2005). Most bacteria either pathogenic or nonpathogenic can grow and multiply in milk due to its high nutrient contents resulting in objectionable physical changes in milk that render it of inferior quality or unfit for human consumption (Asamenew et al., 2012).

However, neither the origin nor the etiological role of raw dairy milk to human E. coli infection has been clarified clearly in our country. In this study, we examined whether dairy milk in the farms and local market act as a source of human E. coli. A total of 50 milk samples, 25 samples from local market, 25 samples from dairy farm were examined for the presence of $E$. coli and the drug resistance status of the isolated strains also divulged.

\section{Materials and Methods}

\section{Sample Collection}

We collected 25 dairy raw milk samples from five different villages and 25 samples from respective village linked five local markets located in Jessore district in the southwestern climatic zone of Bangladesh. We used sterile container for sample collection and transportation and each sample contained $150 \mathrm{ml}$ of fresh raw milk. In addition, we made a survey among 50 participant in the study area by a cross sectional questionnaire including their educational qualification, personal sanitary condition, source of drinking water, consumption of raw milk and milk products to elucidate the awareness of the peoples in that zone of the country.

\section{Determination of Total Aerobic Mesophilic Count and Coliform Count}

To determine the total viable count of milk samples, $0.1 \mathrm{ml}$ of each ten-fold dilution was transferred and spread on plate count agar (PCA) using a sterile glass spreader (Erkmen, 2015). The plates were then incubated at $37^{\circ} \mathrm{C}$ for 24 hours. Following incubation, plates exhibiting 30- 300 colonies were selected to count. The average number of colonies in a particular dilution was multiplied by the dilution factor to obtain the TAMC according to ISO (1995). The results were expressed as colony forming units per $\mathrm{ml}(\mathrm{CFU} / \mathrm{ml})$ of milk sample. The procedures for coliform count (CC) were similar to those followed in TAMC except MacConkey agar was used.

Isolation of E. coli

A quantity of $0.1 \mathrm{ml}$ inoculums from dilutions was used by spread plate technique on Eosin Metheline Blue agar (EMB) (Himedia, India). Incubated at $37^{\circ} \mathrm{C}$ for 24 hours. Typical characteristics colony of E. coli on EMB agar as greenish metallic sheen was enumerated and isolated by sub culturing into EMB. Isolated organisms with supporting growth characteristics of $E$. coli were subjected to Gram's staining, sugar (dextrose, fructose, maltose, lactose and sucrose) fermentation, methyl redvoges proskauer test (MR-VP) and indole production test following the procedure mentioned by (Erkmen, 2015).

\section{Antibiotic Sensitivity Test}

Antibiotic sensitivity test of isolated E. coli was performed with standardized commercial antibiotic discs (Oxoid, UK) following Disc Diffusion Method (Bauer et al., 1966). Sensitivity to antibiotic was studied on Muller Hinton agar plates (Himedia, India) with ampicillin $(10 \mu \mathrm{g} / \mathrm{disc})$, chloramphenicol $(30 \mu \mathrm{g} / \mathrm{disc})$, ciprofloxacin $(5 \mu \mathrm{g} / \mathrm{disc}), \quad$ gentamicin $(10 \mu \mathrm{g} / \mathrm{disc}), \quad$ cephalexin $(30 \mu \mathrm{g} / \mathrm{disc})$. An amount of $0.1 \mathrm{~mL}$ freshly grown pure culture of $E$. coli in nutrient broth (turbidity was compared with $0.5 \mathrm{McF}$ arland standards) was poured on agar plates and allowed to spread gently over the entire surface with a glass rod spreader. After 5 minutes, the discs were placed at a distance of about $1 \mathrm{~cm}$ apart and incubated at $37^{\circ} \mathrm{C}$ for overnight. Based on the diameter of zones of inhibition produced around the antibiotic discs the inhibitory effect of the antibiotic to the growth of the culture was recorded and analyzed according to CLSI (2007) (Table 1).

\section{Statistical Analysis}

The data on total viable count and total coliform count of market and farm milk samples were analyzed in completely randomized design (CRD) and test using SPSS Software (Version 16, 2007). Correlation between total viable count and total coliform count were also evaluated by Pearson Correlation Coefficient method.

\section{Result}

We conducted the survey among 50 participant in the study area by a cross sectional questionnaire which enclosed their educational qualifications, animal rearing system, sanitary condition, source of drinking water, consumption of raw milk and milk products to clarify the awareness of the peoples in that zone of the country. Among the participant, $88 \%$ were literate from primary to junior high school, only $22 \%$ of them used deep tube well for drinking water, while $66 \%$ tube well were close to the toilet and $56 \%$ respondent rear dairy cow in intensive system, $12 \%$ of them drink/eat raw milk and milk products (Table 2 ).

Table 1 Diameter of zone of inhibition for E. coli*

\begin{tabular}{l|ccc}
\hline \multicolumn{1}{c|}{ Antibiotic } & Sensitive $(\geq \mathrm{mm})$ & Intermediate resistance $(\mathrm{mm})$ & Resistance $(\leq \mathrm{mm})$ \\
\hline Ampicillin & 17 & $14-16$ & 13 \\
Gentamicin & 15 & $13-14$ & 12 \\
Ciprofloxacin & 21 & $16-20$ & 15 \\
Chloramphenicol & 18 & $13-17$ & 12 \\
Cefotaxime & 18 & $15-17$ & 14 \\
\hline
\end{tabular}

*Source: Clinical and laboratory standard institute (CLSI), 2007. 
Table 2 Socio economic conditions of the farmers in study area

\begin{tabular}{l|lc}
\hline \multicolumn{1}{c|}{ Category } & \multicolumn{1}{c}{ Subcategory } & Percentage (\%) \\
\hline \multirow{4}{*}{ Educational status } & Illiterate & 12 \\
& Able to signature & 18 \\
& Primary & 32 \\
& Secondary & 38 \\
\hline \multirow{5}{*}{ Sources of drinking water } & Deep tube-well & 22 \\
& Shallow tube-well & 78 \\
& Pond/river & 00 \\
& Mineral water & 00 \\
\hline \multirow{3}{*}{ Location of tube well } & Attached to toilet & 56 \\
& Near about toilet & 14 \\
& Far from toilet & 30 \\
\hline \multirow{3}{*}{ Cow rearing systems } & Intensive & 56 \\
& Semi-intensive & 44 \\
\hline \multirow{2}{*}{ Raw milk or products } & Open & 00 \\
\hline & Eating raw products & 12 \\
& Eating processed/boiled & 88 \\
\hline
\end{tabular}

Table 3 Comparison between TAMC and CC in market and farm samples.

\begin{tabular}{|c|c|c|c|c|c|c|c|c|}
\hline \multirow{2}{*}{ Samples } & \multicolumn{4}{|c|}{ TAMC (Log CFU/ml) } & \multicolumn{4}{|c|}{$\mathrm{CC}(\log \mathrm{CFU} / \mathrm{ml})$} \\
\hline & Max & Min & Average & Remarks & Max & Min & Average & Remarks \\
\hline Market milk & 9.62 & 8.35 & 8.98 & $S(P=000021)$ & 6.69 & 00 & 4.20 & NS $(P=0.071)$ \\
\hline Farm milk & 9.34 & 8.04 & 8.68 & $S(P=0.00021)$ & 6.60 & 00 & 3.03 & $\mathrm{NS}(\mathrm{P}=0.0 / 1)$ \\
\hline
\end{tabular}

Total Aerobic Mesophilic Count and Coliform Count

Highest total aerobic mesophilic count in market milk was $9.62 \log \mathrm{CFU} / \mathrm{ml}$, while coliform count was $6.69 \log$ $\mathrm{CFU} / \mathrm{ml}$. In the farm milk samples, highest total aerobic mesophilic count was $9.34 \mathrm{log} \mathrm{CFU} / \mathrm{ml}$ and coliform count was $6.60 \log \mathrm{CFU} / \mathrm{ml}$. The total aerobic mesophilic count in market milk samples were significantly higher than farm milk samples in $\mathrm{t}$ test $(\mathrm{P}<0.05)$. There is no significant difference between coliform count in market milk samples and farm milk samples (Table 3).

Correlation Between Total Aerobic Mesophilic Count and Coliform Count

The result presented in Fig. 1 revealed positive correlations between TAMC and $\mathrm{CC}$ in market milk samples. Abruptly a weak relationship was observed between TAMC and CC. The value of correlation coefficient was $\mathrm{R}^{2}=0.0013$ and $\mathrm{R}=0.0365$ and regression equation was, $\mathrm{y}=0.1903 \mathrm{x}+2.4992$. The result presented in Fig. 2 showed negative correlation between TAMC and CC of farm milk samples. The value of correlation coefficient was $\mathrm{R}^{2}=0.0105$ and $\mathrm{R}=0.1026$ and regression equation was, $\mathrm{y}=-0.643 \mathrm{x}+8.5399$.

Detection of E. coli

All the isolates upon overnight incubation at $37^{\circ} \mathrm{C}$ produced greenish black colored colonies with characteristic metallic sheen on EMB agar and large bright pink colored colonies with lactose fermentation on MacConkey agar (Kalin et al., 2012).

In Gram's staining, the morphology of the isolated bacteria exhibited Gram-negative short rod arranged in single or paired. All the isolates fermented five basic sugars with the production of both acid and gas. The isolates were positive to $\mathrm{MR}$ and indole production but negative to VP test. Among the collected samples, $66 \%$ (33/50) possessed E. coli and the organism was more prevalent in market milk $(76 \%, 19$ of 25$)$ than farm milk $(56 \%, 14$ of 25$)$.

\section{Antibiotic Resistance Pattern}

We used five common antibiotics for the antibiogram of the isolated E. coli. Based on zone of inhibition, all of the isolates were found to be sensitive against ciprofloxacin, gentamicin and chloramphenicol while resistant to ampicillin and cefotaxime (Fig. 3)

\section{Discussion}

The demand for safe fresh milk is rising in the country with the increasing education and awareness. However, the hygienic condition of raw milk sold in local market of Bangladesh is unknown. There is no surveillance system in milk market or dairy farms in the country. If proper hygienic practice in milk collection and marketing are not followed, it might be a source of zoonotic organisms and cause serious health hazards to human (Ray and Bhunia, 2007). The E. coli contamination found in raw milk might be due to cross contamination of milk with feces or lack of hygienic measures during collection and processing of milk. There are some reports of isolation of E. coli from rectal swab of bovine animals throughout the world; Ogunleye et al. (2013) reported a prevalence of $80 \% E$. coli in apparently healthy cattle in Nigeria, Wang et al. (2013) informed $75 \%$ prevalence of E. coli in bovine feces collected from Japan. 


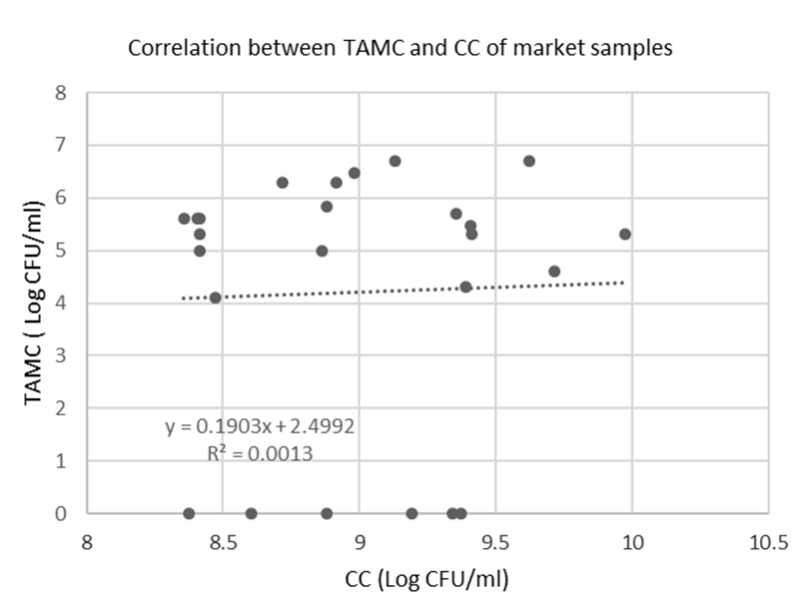

Figure 1 The correlation between TAMC and $\mathrm{CC}$ of market samples.

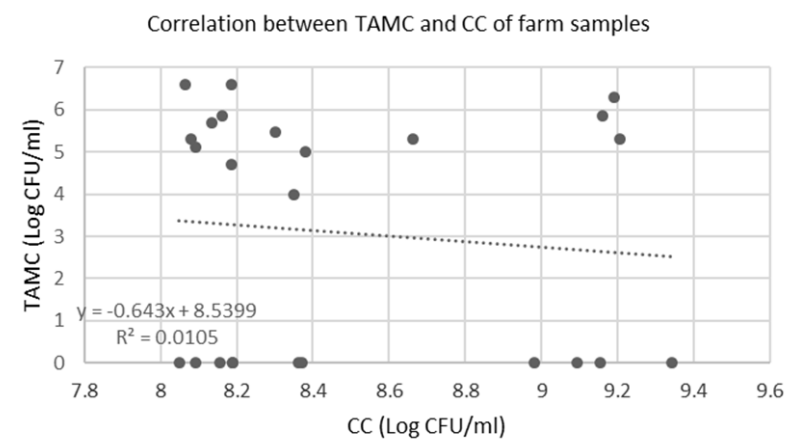

Figure 2 The correlation between TAMC and CC of farm samples

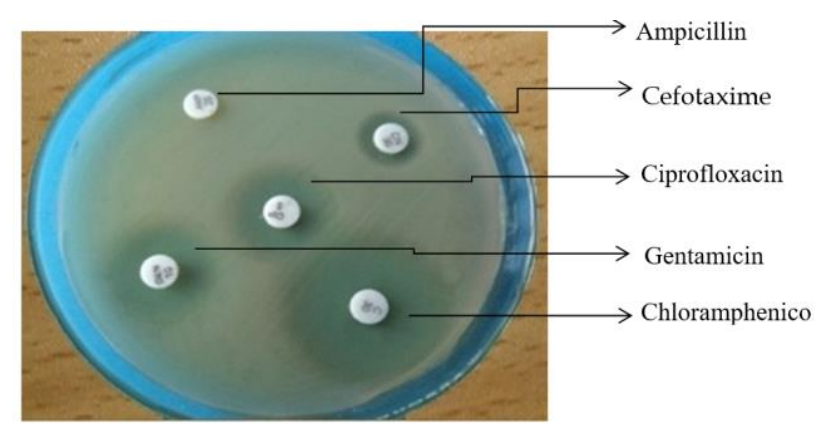

Figure 3 Antibiotic sensitivity pattern

In Bangladesh, the prevalence of $E$. coli was $23.21 \%$ in apparently healthy cattle (Masud et al., 2012). We found, $75 \%$ rectal swabs of cattle in Bangladesh harbor $E$. coli (Hassan et al, 2014). This pathogen has also been isolated from different other sources in the country by other researchers like water (Nazir et al., 2005) broiler birds (Mamun et al., 2016; Khatun et al., 2015) and layer birds (Himi et al., 2015). As the pathogen is present in feces of all mammals and birds, water and other food particles, chances of contamination of milk is high. Fecal contamination of milk could be a serious public health problem in Bangladesh but the microbiological study on dairy milk is scanty in the country. Tanzin et al. (2016) isolated $9 \%$ E. coli from dairy milk and buffalo milk in Bangladesh. However, these studies was limited in one dairy farm only, in addition they did not covered the local milk market of the country. However, we studied market milk besides farm milk because the milk can be contaminated in different stages of marketing also. Alam et al. (2017) isolated E. coli from milk samples marketed at another geographical area of Bangladesh, (Chittagong). Hadrya et al. (2012) found $4.2 \times 10^{7} \mathrm{CFU} / \mathrm{ml}$ of coliform count from raw milk at Morocco. In addition, Aaku et al. (2004) and Arenas (2004) observed that the total viable count in raw milk sample was $5.5 \times 10^{6} \mathrm{CFU} / \mathrm{ml}$. Hossain et al. (2017) examined pasteurized, unpasteurized and UHT milk samples at greater Mymensingh area of Bangladesh and reported about log 7.4 TVC with log 3.5 $\mathrm{CC}$ on average in all milk samples. The TAMC and CC in market milk were $8.98 \mathrm{log} \mathrm{CFU} / \mathrm{ml}$ and $4.20 \mathrm{log} \mathrm{CFU} / \mathrm{ml}$ in our study, which was higher than previous studies; it might be due to insanitary condition during marketing of milk, since the TAMC and CC were not so high among farm milk of our study. Zeinhom and Abdel-Latef (2014) stated that E. coli was detected in 26.7 and $16 \%$ of the milk sampled from markets and farms of Egypt, respectively. Alam et al. (2017) isolated E. coli from 18 and $12 \%$ market milk and farm milk at Chittagong region of Bangladesh. Hossain et al. (2017) isolated E. coli from $32 \%$ milk samples in Mymensingh region of Bangladesh. In this study, we isolated 66 and $56 \%$ E. coli from market milk and farm milk respectively. This variation might be due to different geographical location, hygienic condition followed by farmers and all personnel in the milk marketing chain, different study methods also can differ the result.

Drug resistance pathogens have been increasing worldwide, leading to failures in treatment of infectious diseases in human and mammals. Uddin et al. (2011) isolated E. coli from raw milk in Dhaka city of Bangladesh and reported that the isolates were 100\% resistant against rifampin and tetracycline while 50\% resistant against nalidixic acid. Tanzin et al. (2016) isolated gatifloxacin resistant $E$. coli from milk samples in Mymensingh region of Bangladesh while Hossain et al. (2017) reported amoxicillin and erythromycin resistant $E$. coli from milk samples in this region. The isolates in our study also exhibited resistant to ampicillin and cefotaxime, which is supported by the previous studies of other researchers in the country.

\section{Conclusion}

The present study indicated that the raw milk samples in the study area are highly contaminated in both farm and local market. The problem of drug resistant bacteria is a matter of concern globally especially in developing countries, where animals live in closer to human, unaware people drink raw milk and milk products and chances of transmission of drug resistant pathogen from animal to human is high. The indiscriminate use of antibiotics in dairy animals and every steps in milk collection, processing, marketing should be closely monitored. Molecular characterization of E. coli isolates from milk and diarrheal patients in the country is recommended to elucidate the role of raw milk as a source of human infection in Bangladesh and a routine survey of antibiotic resistance pattern is acknowledged in the country. 


\section{References}

Aaku EN, Collinson EK, Gashe BA, Mpuchane S. 2004. Microbiological quality of milk from two processing plants in Gaborone Botswana. Food Control. 15:181-186.

Arenas RL. 2004. Microbiological and physico-chemical changes in Genestoso cheese, a Spanish acid curd variety, throughout ripening. Food Control. 154:271-279

Alam MK, Akther S, Sarwar N. 2017. An Investigation on Risk Factors Related to the Occurrence of Escherichia coli in Fluid Milk Marketed in Chittagong, Bangladesh. Journal of Food Quality and Hazards Control. 4: 9-13.

Asakura H, Makino S, Kobori H, Watarai M, Shirahata T, Ikeda T, Takeshi K. 2001. Phylogenetic diversity and similarity of active sites of Shiga toxin (stx) in Shiga toxin-producing Escherichia coli (STEC) isolates from humans and animals. Epidemiology and Infection. 127: 27-36.

Asamenew TM, Mahendra P, Addisalem HB. 2012. Bacteriological Study on coliform organisms from Ethiopian Traditional Cheese West Shown Zone, Ethiopia. International Journal of Microbiological Research. 3: 188191.

Aycicek HS, Cairoli K, Stevenson TH. 2005. Incidence of Staphylococcus aureus in ready to eat meals from military cafeterias in Ankara, Turkey. Food control. 16: 531-534.

Bauer AW, Kirby WMM, Sheris JC, Truck M. 1966. Antibiotic susceptibility testing by a standardized single disc method. American Journal of Clinical Pathology 45:493-496.

Black RE, Cousens S, Johnson HL, Lawn JE, Rudan I, Bassani DG, Jha P, Campbell H, Walker CF, Cibulskis R, Eisele T, Liu L, Mathers C. 2010. Global, regional, and national causes of child mortality in 2008: a systematic analysis. Lancet. 5: 9730.

Cheesbrough M. 1985. Medical laboratory manual for tropical countries. Microbiol. 2:400-480.

Clinical and Laboratory Standards Institute (CLSI, formerly NCCLS) 2007: Performance standards for antimicrobial susceptibility testing. $17^{\text {th }}$ Informational Supplement document M100-S17: 1. Wayne, Pennsylvania. 32-50.

Elder RO, Keen JE, Siragusa GR, Barkocy-Gallagher GA, Koohmaraie M, Laegreid WW. 2000. Correlation of enterohemorrhagic Escherichia coli 0157 prevalence in feces, hides, and carcasses of beef cattle during processing. Proceedings of the National Academy of Sciences of the United States of America. 97: 2999-3003.

Erkmen O, Bozoglu TF. 2016. Food Preservation by Low Temperatures. Food Microbiology: Principles into Practice. John Wiley and Sons, Ltd, Chichester, UK.

Erkmen O. 2015. Basic Methods for the Microbiological Analysis of Foods. Third edition, Nobel Academic Publisher, Turkey.

Hadrya F, Elouardi A, Benali D, Hami H, Soulaymani A, Senouci S. 2012. Bacterial Quality of Informally Marketed Raw Milk in Kenitra City, Morocco. Pakistan Journal of Nutrition, 11: 760-767.

Hassan J, Nazir KHMNH, Parvej MS, Kamal T, Rahman MT. 2017. Molecular based prevalence of shigatoxigenic Escherichia coli in rectal swab of apparently healthy cattle in Mymensingh district, Bangladesh. Journal of Advanced Veterinary and Animal Research. 4: 194-199.

Hassan J, Parvej MS, Rahman MB, Khan MSR, Rahman MT, Kamal T, Nazir KHMNH. 2014. Prevalence and characterization of Escherichia coli from rectal swab of apparently healthy cattle in Mymensingh, Bangladesh. Microbes and Health. 3: 12-14.

Himi HA, Parvej MS, Rahman MB, Nasiruddin KM, Ansari WK, Ahamed MM. 2015. PCR Based Detection of Shiga Toxin Producing E. coli in Commercial Poultry and Related Environments. Turkish Journal of Agriculture - Food Science and Technology, 3: 361-364.
Hossain MF, Rahman MT, Kabir SML. 2017. Microbial assessment of milk collected from different markets of Mymensingh, Gazipur and Sherpur districts of Bangladesh and determination of antimicrobial resistance patterns of the isolated bacteria. Asian Australian Journal of Food Safety and Security. 1:7-16

Icddrb. 2002. Trends in Aetiologies for Diarrhoeal Diseases, Health and Science Bulletin. 1:12-15.

ISO. 1995. Recommendation of the meeting of the subcommittee, International Organization for Standardization, on meat and meat products. ISO/TC-36/Sc6.The Netherlands.10-18.

Kalin R, Ongor H, Cetinkaya B. 2012. Isolation and molecular characterization of Escherichia coli O157 from broiler and human samples. Foodborne Pathog Dis. 9:313-8.

Kassenborg HD, Hedberg CW, Hoekstra M. 2004. Farm visits and undercooked hamburgers as major risk factors for sporadic Escherichia coli O157:H7 infection: data from a case-control study in 5 FoodNet sites. J Clin Infect Dis. $5: 38-45$.

Khatun MN, Elahi ATMME, Ahmed S, Parvej MS, Akhter S, Ansari WK, Ali MS. 2015. Frequency of drug resistant Escherichia coli isolated from commercial broiler chicken in Bangladesh. International Journal of Natural and Social Sciences. 2: 01-05.

Kosek M, Bern C, Guerrant RL. 2003. The global burden of diarrhoeal disease, as estimated from studies published between 1992 and 2000, Bull World Health Organ. 81:197204.

Uddin MA, Hasan MMH, Noor R. 2011. Isolation and Identification of Pathogenic Escherichia coli, Klebsiella spp. and Staphylococcuss pp. in Raw Milk Samples Collected from Different Areas of Dhaka City, Bangladesh. Stamford Journal of Microbiology.1:19-23

Mamun MM, Parvej MS, Ahamed S, Hassan J, Nazir KHMNH, Nishikawa Y, Rahman MT. 2017. Prevalence and Characterization of Shigatoxigenic Escherichia coli in Broiler Birds in Mymensingh. Bangladesh Journal of Veterinary Medicine. 14: 5-8.

Masud MA, Fakhruzzaman M, Rahman MM, Shah MM, Nazir KHMNH. 2012. Isolation of Escherichia coli from apparently healthy and diarrheic calves in Dinajpur area in Bangladesh and their antibiogram. Journal of the Bangladesh Society for Agricultural Science and Technology. 9: 45-48.

Naidu KG, Gaddad SM, Shivannavar CT, Goud RN, Neogi U, Saumya R. 2007. Prevalence and antibiotic sensitivity of shiga toxin producing Escherichia coli in gulbarga region, India. Trends in Medical Research. 2: 149-154.

Nazir KHMNH, Rahman MB, Nasiruddin KM, Akhtar F, Khan MFR, Islam MS. 2005. Antibiotic sensitivity of Escherichia coli isolated from water and its relation with plasmid profile analysis. Pakistan Journal of Biological Sciences. 8: 16101613.

Ogunleye AO, Okunlade AO, Jeminlehin FO, Apjuwae ATP. 2013. Antibiotic resistance in Escherichia coli isolated from healthy cattle at a major cattle market in Ibadan, Oyo State, South Western, Nigeria. African Journal of Microbiology Research. 7: 4572-4575.

Qadri F, Svennerholm AM, Faruque AS, Sack RB. 2005. Enterotoxigenic Escherichia coli in developing countries: epidemiology, microbiology, clinical features, treatment and prevention. Clinical Microbiology Reviews. 18: 465-483.

Ray B, Bhunia A. 2007. Fundamental food microbiology. CRC press, Boca Raton.

Rehman MU, Rashid M, Sheikh JA, Bhat MA. 2014. Molecular epidemiology and antibiotic resistance pattern of enteropathogenic Escherichia coli isolated from bovines and their handlers in Jammu, India. Journal of Advanced Veterinary and Animal Research. 1: 177-181. 
Smith K, Peter K, Daniela H, Melchior S. 2007. Food borne pathogenic microorganisms and natural toxins. Food drug Administration Center Food Safety. Applied Nutrition. 10: 119-150.

Tulloch J, Richards L. 1993. Childhood diarrhoea and acute respiratory infections in developing countries. Medical Journal of Australia. 159: 46-51

Tanzin T, Nazir KHMNH, Zahan MN, Md. Parvej S, Zesmin K, Rahman MT. 2016. Antibiotic resistance profile of bacteria isolated from raw milk samples of cattle and buffaloes. Journal of Advanced Veterinary and Animal Research. 3: $62-67$
Wang L, Wakushima M, Aota T. 2013. Specific properties of Enteropathogenic Escherichia coli isolates from diarrheal patients and comparison to strains from foods and fecal specimens from cattle, swine, and healthy carriers in Osaka City, Japan. Appl Environ Microbiol. 79:1232-40.

Wang L, Zhang S, Zheng D, Fujihara S, Wakabayashi A, Okahata K, Suzuki M, Saeki A, Nakamura H, HaraKudo Y, Kage-Nakadai E, Nishikawa Y. 2017. Prevalence of diarrheagenic Escherichia coli in foods and fecal specimens obtained from cattle, pigs, chickens, asymptomatic carriers, and patients in Osaka and Hyogo, Japan. Japanese Journal of Infectiuos diseases. 70:464-469.

Zeinhom MMA, Abdel-Latef GK.2014. Public health risk of some milk borne pathogens. Beni- Suef university journal of basic and applied sciences 3: 209-215 